\title{
Methods to eradicate soft tunic syndrome (STS)-causing protozoa Azumiobodo hoyamushi, the highly infectious parasite from the edible ascidian (Halocynthia roretzi)
}

\author{
Ji-Hoon Lee, Jae-Geun Lee, Seung-Ryul Zeon, Kyung-II Park and Kwan Ha Park*
}

\begin{abstract}
Although soft tunic syndrome (STS) in the ascidian is a serious disease, helpful measures have yet not been established. It was examined in this study by applying aniti-parasitic drugs to eradicate the causative protozoa Azumiobodo hoyamushi from infected ascidians. Formalin was synergistic in killing parasites in vitro when co-treated with hydrogen peroxide $\left(\mathrm{H}_{2} \mathrm{O}_{2}\right)$ or bronopol, but not with chloramine-T or povidone-iodine (PVP-I), when tested with in vitro parasite culture. The synergistic effects did not change when formalin- $\mathrm{H}_{2} \mathrm{O}_{2}$ (or bronopol) ratios were changed. It was found that treatment periods less than 60 min achieved a sub-maximal efficacy. Increasing drug concentration while keeping 30 min period improved anti-parasitic effects. Anti-parasitic effects of formalin $(\mathrm{F})+\mathrm{H}_{2} \mathrm{O}_{2}(\mathrm{H})$ were also assessed in an in vivo STS model infected with cultured parasites. It was observed that combined $50(40 \mathrm{~F}+10 \mathrm{H})$ and $100(80 \mathrm{~F}+2 \mathrm{OH})$ ppm were effective in partially preventing STS-caused mortality. In horizontally transmitted artificial STS model, significant prevention of ascidian mortality was also observed after 50 ppm. Marked reduction of living parasites were noted after drug treatments in vivo. The results provide a highly useful basis to develop a preventive or treatment measure against the currently uncontrollable STS in the ascidian.
\end{abstract}

Keywords: Ascidian Halocynthia roretzi, Azumiobodo hoyamushi, Formalin, Hydrogen peroxide, Synergistic effects, Mortality

\section{Background}

Starting from the late 1980's, soft tunic syndrome (STS) has become one of the most notorious nuisances in Korean ascidian culture industry (Kim et al. 2014). The disease is now known to be caused by a protozoan pathogen Azumiobodo hoyamushi (A. hoyamushi). This parasite resides within the tunic tissue leading to disintegration of the cellulose-based exoskeleton structure of the ascidian (Kumagai et al. 2010, 2011; Kim et al. 2014). It has been reported that the parasite is opportunistic in plaguing the cultured ascidian, but the pathogen has

\footnotetext{
* Correspondence: khpark@kunsan.ac.kr
Department of Aquatic Life Medicine, College of Ocean Science and

* Correspondence: khpark@kunsan.ac.kr
Department of Aquatic Life Medicine, College of Ocean Science and Technology, Kunsan National University, Miryong-dong San-68, Gunsan City, Jeonbuk 573-701, Korea
}

(C) 2016 Lee et al. Open Access This article is distributed under the terms of the Creative Commons Attribution 4.0 International License (http://creativecommons.org/licenses/by/4.0/), which permits unrestricted use, distribution, and reproduction in any medium, provided you give appropriate credit to the original author(s) and the source, provide a link to the Creative Commons license, and indicate if changes were made. The Creative Commons Public Domain Dedication waiver (http://creativecommons.org/publicdomain/zero/1.0/) applies to the data made available in this article, unless otherwise stated.

also been reported to be present in other similar marine animals.

While the disease is severely affecting ascidian industry to the extent that even its sustainability is threatened, still there is no effective measure to control the disease. One way that can be considered to resolve this predicament is to utilize various currently available biocidal agents. In our previous report (Park et al. 2014), it was demonstrated that several biocidal drugs are effective in killing the causative protozoa both in vivo and in vitro. Judging simply from the potency and toxicity of drugs tested, several drugs including formalin, hydrogen peroxide $\left(\mathrm{H}_{2} \mathrm{O}_{2}\right)$ and bronopol, in single treatments, were found promising deserving detailed researches.

In the present study, we examined the co-treatment effects of drugs which are singly efficacious in killing the 
parasites. When two agents are simultaneously applied to kill pathogens, one agent can influence the efficacy of the other (Klaasen 2001). What is ideal for treatment is a synergistic treatment activity with accompanying minimal toxicity to the host. To be synergistic two drugs need to act on different effector systems or exert by different action mechanisms (Mutschuler and Derendorf 1995). In contrast, however, if the two drugs scavenge each other, the net effect can be lower than their arithmetic sum.

In view of the weakness that most non-specific disinfectants have narrow margin of safety (Maris 1995), we aimed to examine combinational effects of anti-parasitic agents with a hope to identify synergistic activities. Effects were evaluated both in pure cultured parasites $A$. hoyamushi in vitro, and also in artificially infected ascidians in vivo to delineate the applicability of developed methods in the farm.

\section{Methods}

Chemicals

Chloramine-T hydrate (chloramine), bronopol, povodoneiodine (poly-vinylpyrrrolidine-iodine complex, PVV-I) were purchased from Sigma Co. (St. Louis, MO, USA). Formaldyhyde solution (37 \%) and hydrogen peroxide (35\%) were obtained from Junsei Co. (Tokyo, Japan). All other main chemicals not specified were also obtained from Sigma.

\section{Parasite culture}

The pathogenic parasite A. hoyamushi was isolated from tunics of diseased ascidians as described previously (Park et al. 2014). Isolated pathogens were incubated at $15{ }^{\circ} \mathrm{C}$ in minimum essential medium (MEM) supplemented with fetal bovine serum, glutamine, penicillin, sea salt, streptomycin, and HEPES buffer. Prepared medium was filtered through $0.45 \mu \mathrm{m}$ filter papers.

\section{In vitro anti-parasitic effects of drugs in pure parasite culture}

Pure culture of $A$ hoyamushi was grown in MEM for $3-4$ days to the cell density of about $1 \times 10^{8} / \mathrm{ml}$. After adjustment to $5 \times 10^{5}$ cells $/ \mathrm{ml}$, the culture was added to 12 -well plates in $1-\mathrm{ml}$ volume and incubated with test drug solutions at different concentrations and exposure periods. To estimate parasite-killing effects of drugs, 200 cells were randomly counted with a reverse phase microscopy at 400-fold magnification.

In vivo anti-parasitic effects of drugs in artificially infected ascidians

Apparently healthy ascidians weighing about $70 \mathrm{~g}$ were transported from a culture farm located in Tongyong City, Kyungnam Province, Korea. They were kept in the laboratory at $15{ }^{\circ} \mathrm{C}$ and 30.5 psu for 1 week to acclimatize. Cultured parasites of $1.0 \times 10^{7}$ cells were added into the 100-1 ascidian-containing aquaria and maintained until mild symptoms (Kimura scale, Kitamura et al. 2010) developed in about $20 \%$ of organisms (took about 3 days). Thirty individuals each were randomly allocated to 20-L aquaria in the absence and presence of test drugs. Exposures were performed only once on day 1 at necessary drug concentrations and exposure periods. Mortality of the ascidians was monitored for 14 days thereafter. During the exposure, number of live parasites in the tunics was estimated with some ascidians. This experiment was performed in two separate sets of experiments due to difficulties of obtaining non-infected colonies: the first was with 50 and 100 ppm of combined drugs and the second with $20 \mathrm{ppm}$. The whole procedure of in vivo assessments was conducted according to the Ethics Codes of the Animal Experiment Approval Committee, Kunsan National University, Korea.

\section{In vivo anti-parasitic effects of drugs in horizontally- infected ascidians}

Both healthy and diseased ascidians were transported from culture farms of different locations in Tongyong City. Healthy individuals (30 individuals, about $80 \mathrm{~g}$ body weight) were maintained with six severe grade ascidians (about $80 \mathrm{~g}$ ). The healthy ascidians were kept hanging with the ropes similarly to the situation used in the farm. The ropes were about $50 \mathrm{~cm}$ long and were perpendicularly maintained at $15{ }^{\circ} \mathrm{C}$. When about $20 \%$ of animals exhibited mild STS signs, ascidians were immersed into the drug bath for $1 \mathrm{~h}$ on day 1 before starting monitoring mortality. At the termination of mortality observation, the number of live parasites in the tunic was estimated.

\section{Estimation of live parasites in the tunic}

The method was basically identical to that described previously (Park et al., 2014). In short, ten individuals were randomly selected from each group and the whole tunic tissue was isolated. The tunics were immersed in 20-ml filter-sterilized sea water and incubated for $24 \mathrm{~h}$ at $15{ }^{\circ} \mathrm{C}$. Total live cell counting was made using a hemacytometer and light microscope.

\section{Results}

In vitro anti-parasitic effects of drugs in pure parasite cultures

Based on previous anti-parasitic effects (Park et al. 2014) of various drugs, formalin, $\mathrm{H}_{2} \mathrm{O}_{2}$ and bronoplol, chloramines- $\mathrm{T}$ (referred to chloramines) and povidoneiodine (PVP-I) were selected for combinational potency measurements. Figure 1 illustrates in vitro parasite-killing effects of test drugs when combined with formalin and 


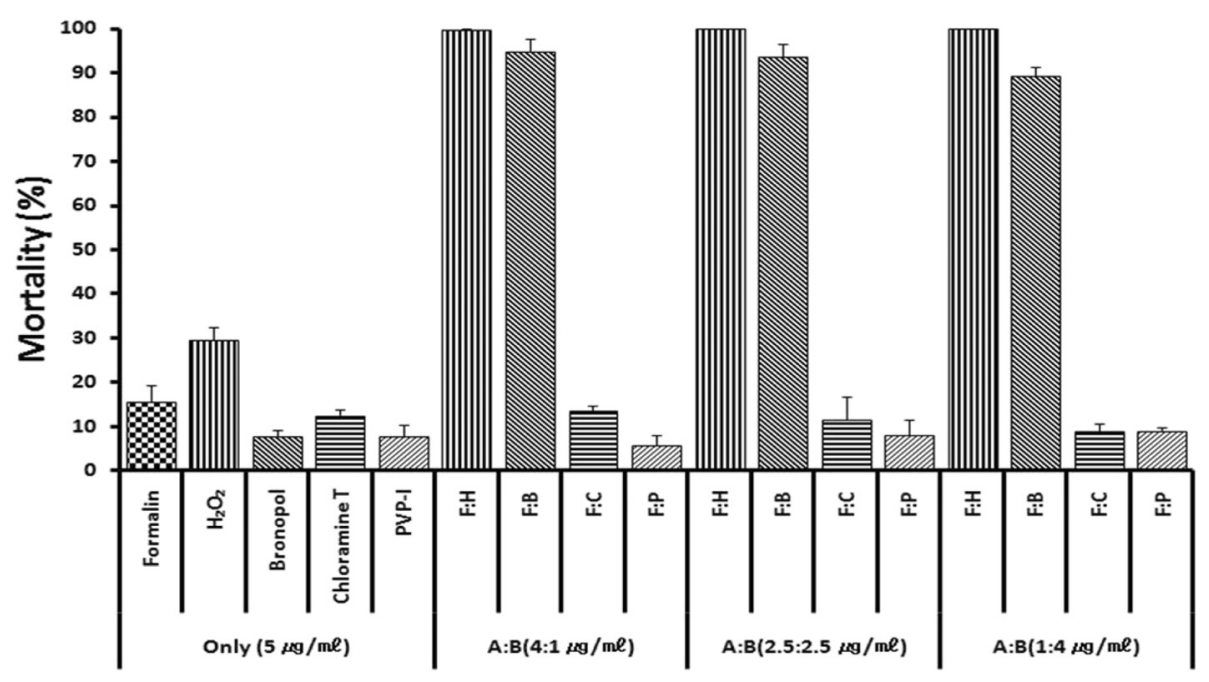

Fig. 1 In vitro anti-parasitic effects singly and in combinations. Parasites were exposed to test drugs for 60 min singly or in combinations of two drugs. PVP-I povidone iodine, F:H formalin- $\mathrm{H}_{2} \mathrm{O}_{2}, \mathrm{~F}-\mathrm{B}$ formalin-bronopol, F:C formalin-chloramine-T, F:P formalin-PVP-I. Ratios in combinations were 4:1, $2.5-2.5$, or $1: 4$ ppm. $n=3$

treated for $60 \mathrm{~min}$. In the single $5 \mathrm{ppm}$ exposure with formalin, hydrogen peroxide $\left(\mathrm{H}_{2} \mathrm{O}_{2}\right)$, bronopol, chloramine and PVP-I, all drugs exerted parasite-killing effects of $8-31 \%$. However, combinations of formalin $+\mathrm{H}_{2} \mathrm{O}_{2}$ or formalin + bronopol exhibited strong synergistic effects. Synergistic effects were not observed in formalin + chloramine or formalin + povidone-iodine combinations.

\section{Effect of different exposure period and exposure concentrations in vitro}

Exposure period of $60 \mathrm{~min}$ is likely to be an obstacle in on-site field applications, and thus it must be better if possible to shorten it. In order to evaluate shorter exposures, parasites were exposed in vitro for 20-60 min with 4:1 ppm standard combinations of formalin- $\mathrm{H}_{2} \mathrm{O}_{2}$ or formalin-bronopol. As results in Fig. 2a indicate, 20-40 min exposure could only exert a slightly compromized activity indicating that $60 \mathrm{~min}$ is the requirement with 4 ppm.

Another option to compensate the submaximal efficacy of shorter drug exposure can be increasing drug concentrations. When formalin- $\mathrm{H}_{2} \mathrm{O}_{2}$ (or bronopol) concentration was escalated from $5 \mathrm{ppm}$ (total) to $20 \mathrm{ppm}$, generally there was a concentration-dependent increase in parasiticidal activity (Fig. 2b). In adition, exposure with $10 \mathrm{ppm}$ was more effective than $5 \mathrm{ppm}$ with formalin- $\mathrm{H}_{2} \mathrm{O}_{2}$ but not with formalin-bronopol.

In vivo anti-parasitic effects of drugs in infected ascidians After infection with pure cultured parasites, ascidians were bathed for $1 \mathrm{~h}$ in formalin- $\mathrm{H}_{2} \mathrm{O}_{2}$ combinations at 20, 50 and $100 \mathrm{ppm}$ (total). Figure 3 illustrates drug effects on mortality after an artificial infection with parasites to non-infected, healthy ascidians. As the tests were performed in two separate sets, the control mortalities were not identical being that of control in $20 \mathrm{ppm}$ was slightly higher than in 50 and $100 \mathrm{ppm}$.

The starting time point for drug testing was when there was a clear appearance of STS signs in about $20 \%$ of animals. Clear reduction in ascidian mortality was obtained with 50 (Fig. 3b) and 100 ppm (Fig. 3c), but not with 20 ppm (Fig. 3a). During the mortality observation period of 14 days, number of live parasites in the tunic tissue was enumerated. It was observed that there were about an average of 20,000 parasites/ascidian on day 5 from the start of monitoring, and the number increased significantly on day 10 to about 80,000 without treatment (see Fig. 4, Control columns). These live parasites were almost completely removed when ascidians were bathed with $50 \mathrm{ppm}$ of formalin- $\mathrm{H}_{2} \mathrm{O}_{2}$ once for $1 \mathrm{~h}$ on day 1 (Fig. 4, Treated columns).

Similar in vivo anti-parasitic effects were identified in another STS model in which infection was achieved by co-incubation with diseased individuals. In the two independent trials with 55-60 ascidians in each treatment group, formalin- $\mathrm{H}_{2} \mathrm{O}_{2}$-treated groups (50 ppm total) demonstrated apparently better survivals (Fig. 5). While the mortality was above $80 \%$ without treatment by day 14 , mortalities of about $30 \%$ (Trial \#1) and $5 \%$ (Trial \#2) were respectively observed. In this horizontal transmission model, too, significant reduction in live parasites was confirmed (right-sided two panels in Fig. 5).

\section{Discussion}

It is urgently required to invent methods to control the spread of STS disease, the one most devastating cause 


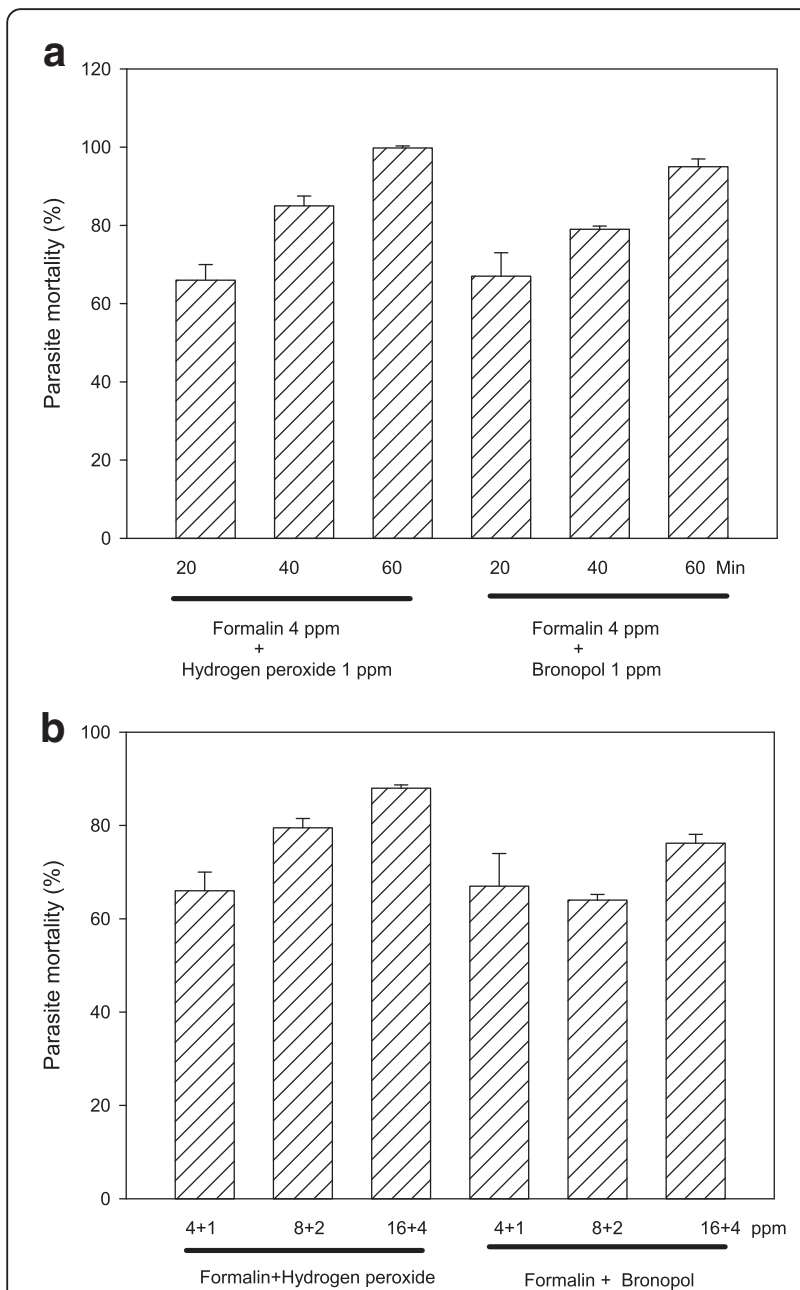

Fig. 2 In vitro anti-parasitic effects of different exposure periods and different drug concentrations. For different exposure period, parasites were exposed for 20,40 and 60 min with formalin $-\mathrm{H}_{2} \mathrm{O}_{2}$ or formalinbronopol combinations a. For different concentrations, parasites were exposed for 30 min with formalin- $\mathrm{H}_{2} \mathrm{O}_{2}$ and formalinbronopol at 5, 10 or $20 \mathrm{ppm}$ of total drug concentrations $\mathbf{b}$. The ratios in both tests were 4:1 ppm. $n=3$

currently impacting ascidian (squirt) industry. Different methods have been explored in the pursuit of resolving the predicament, and some examples are farm rotation (Kim et al. 2014), genetic selection of more tolerant individuals (Cho et al. 2008) and present trials to move farms to the far open sea areas. Treatment of the culture animals with biocidal drugs can be considered as one option for this purpose.

In this study, it was assessed whether dual biocide treatment can be a better choice to increase efficacy of the drugs. The choice of test drugs were based on two criteria: (1) effectiveness of drugs in single treatment from previous studies (Park et al. 2014; Lee et al. 2013); (2) availability and legal uses for aquacultural purposes. Dual treatment has not been often adopted in using
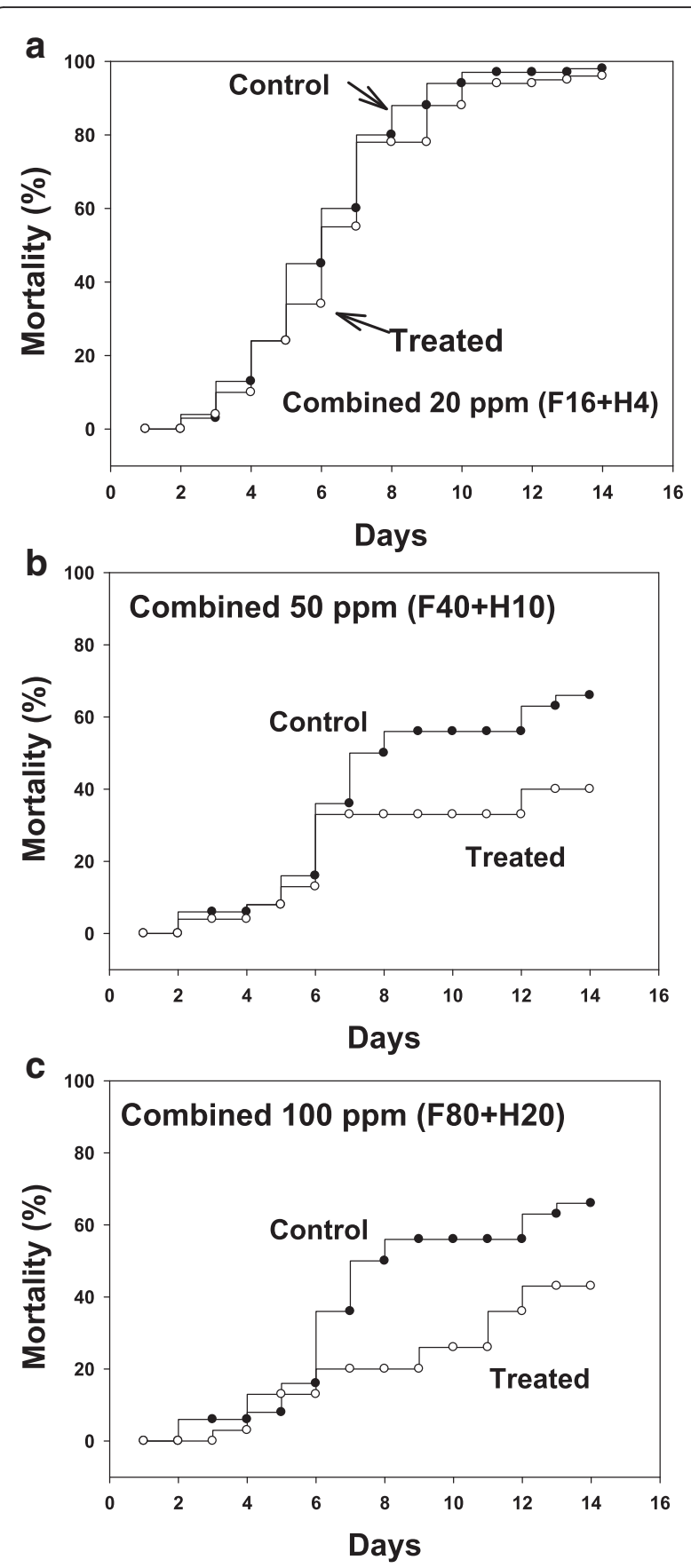

Fig. 3 In vivo anti-parasitic effects of formalin- $\mathrm{H}_{2} \mathrm{O}_{2}$ combination against parasite culture-induced STS model. STS was induced by adding pure culture of parasites to aquaria until about $20 \%$ of ascidians exhibit mild symptoms. Data in $\mathbf{b}$ and $\mathbf{c}$ were obtained in the same set of experiment, whereas those of panel a were from an additional set. Statistical significance was found between control and drug treatment in $\mathbf{b}$ and $\mathbf{c}$ (Fisher's exact test for final mortality, $p<0.05) \cdot n=30$

non-specific biocides in contrast to the frequent uses of antibiotics to achieve synergistic advantage in aquaculture (Smith 2012). Only limited reports are available 


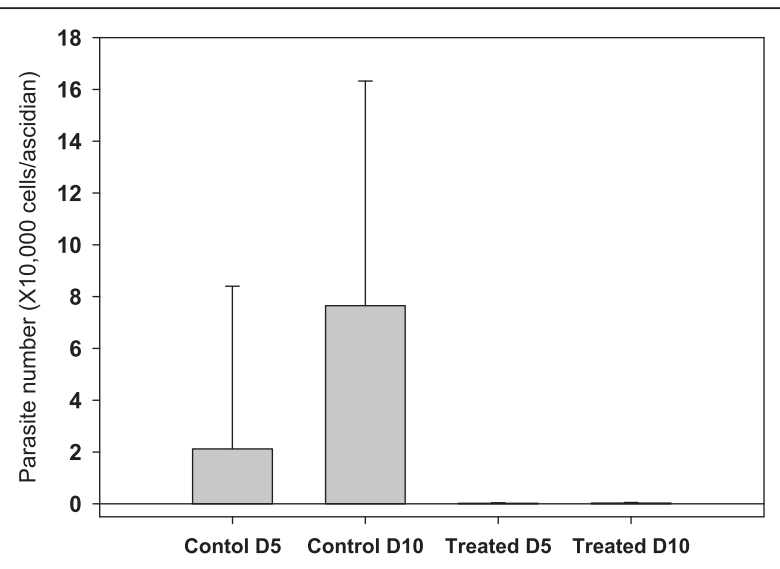

Fig. 4 Effects of formalin- $\mathrm{H}_{2} \mathrm{O}_{2}$ combination on live parasite numbers. Ascidians from the in vivo STS experiment (refer to Fig. 3) were used. D5, day 5; D10, day 10. Statistical analysis with ANOVA followed by Newman-Keul's test revealed significance between control and treatment for each corresponding time point. $n=10$

which suggest synergism in biocidal drug use use. Synergistic anti-parasitic effects were demonstrated when formalin and malachite green were simultaneously treated against the protozoal pathogen Tetrtahymena pyriformis (Gilbert et al. 1979). Combination of sulfonamides with neomycin also exerted potentiated effects against the protozoal parasite Labyrinthuloides haliotidis in abalone (Bower 1989). In addition, synergistic activities were identified in the combinations of formalin + bronopol or formalin + MBT (a cactus extract) against the salmon egg-infecting fungus (Jee and Lee 2009).

Formalin is one of the most widely used non-specific biocides worldwide to treat aquatic pathogens including protozoa (Treves-Brown 2000). This disinfectant is approved for olive flounder and eggs by bath treatments in Korea. Bronopol (bromo-2-nitropropane-1,3-diol) is effective against protozoan parasites, such such as Icthyophthirius multifiliis (Shinn et al. 2012a, b). This drug has not, however, been introduced to Korean aquaculture, yet. Due to its quick decomposition into water and gaseous oxygen after application, $\mathrm{H}_{2} \mathrm{O}_{2}$ is very safe to culture animals and human consumers (Treves-Brown 2000). This drug is used in general to sanitize culture water. $\mathrm{H}_{2} \mathrm{O}_{2}$ has shown promising results in treating different protozoan parasites (Harms 1996; Russo et al. 2007). In this study, synergistic actions were identified with formalin- $\mathrm{H}_{2} \mathrm{O}_{2}$ or formalin-bronopol combinations. No clear synergism was observed with formalin-chloramine and formalin-PVP-I combinations.

Synergistic activities are closely related to action mechanisms of the two drugs. To be synergistic, one
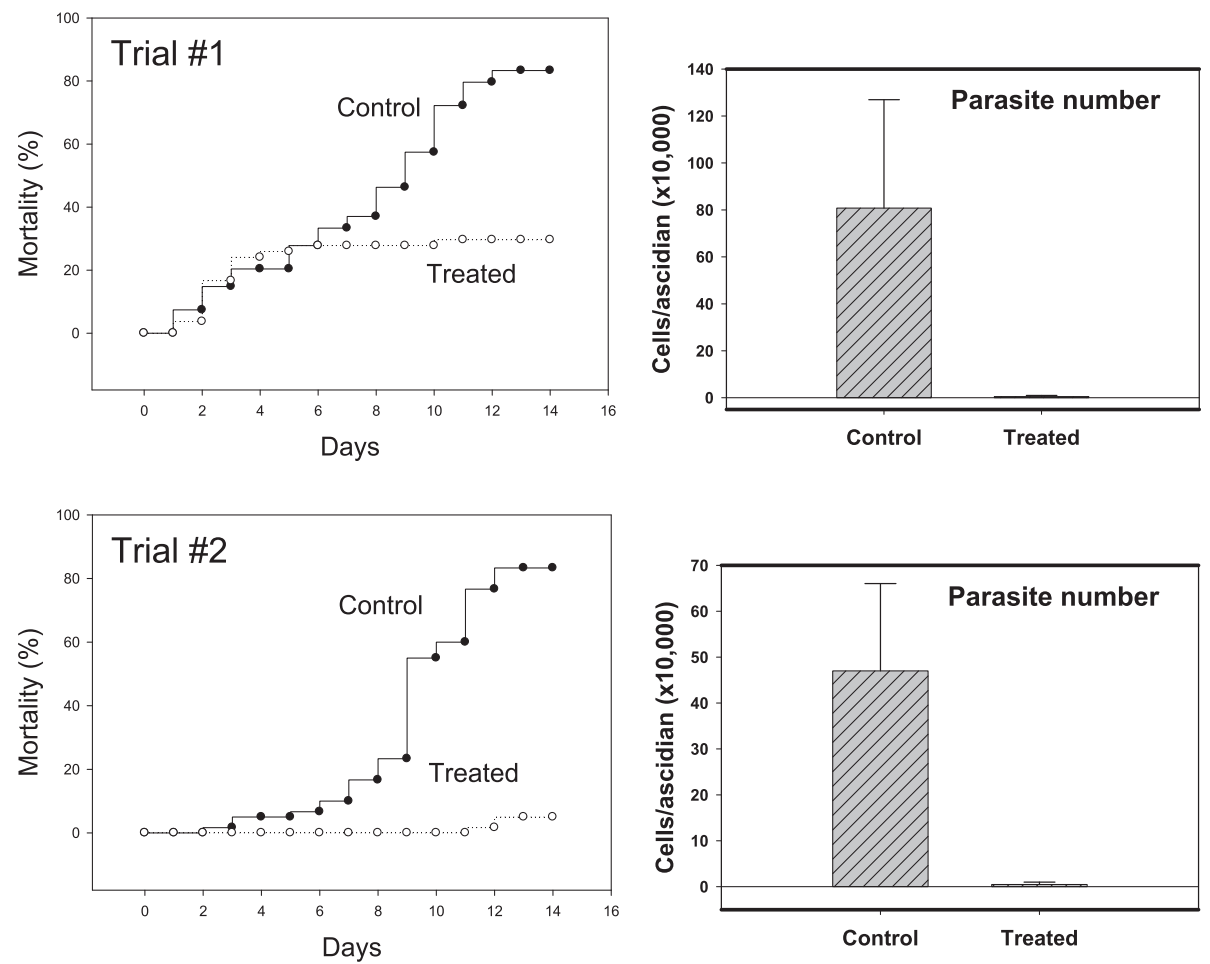

Fig. 5 In vivo anti-parasitic effects of formalin $-\mathrm{H}_{2} \mathrm{O}_{2}$ combination on STS model induced by horizonal transmission. STS was induced by keeping healthy ascidians with severely diseased individuals until about $20 \%$ of ascidians exhibit mild symptoms. Live parasite numbers were examined on surviving ascidians until day 14. Statistical significance was found between control and drug treatment in both trials (Fisher's exact test for final mortality, $p<0.05) . n=55$, Trial $\# 1 ; n=60$, Trial \#2 
drug should enhance the binding of another drug to target sites, or enhance transport to target areas. However, it is almost impossible to expect the occurrence of synergism in a straightforward way because numerous factors are involved until eventual death of parasites occurs (Bell 2005). Experimental demonstration is always needed.

Formalin (formaldehyde) denatures vital biomolecules working as a bridge irreversiblly by liking two amine groups between adjacent molecules (Mason and O'Leary 1991). While bronopol causes membrane damage in organisms through the inhibition of membrane bound enzymes (Stretton and Manson 1973). On the other hand, $\mathrm{H}_{2} \mathrm{O}_{2}$ releases reactive oxygen species to denature proteins and lipids in the organisms (Maris 1995). The dissimilarity in mechanisms involved in the combinations of formalin- $\mathrm{H}_{2} \mathrm{O}_{2}$ and formalin-bronopol seemed to satisfy necessary conditions for synergism. From unknown reasons, yet, synergism was not observed with chloramine and PVP-I, both of which commonly produce reactive halogen radicals as their action mechanism (McDonnell and Russell 1999).

From the current finding, it was found important to keep the bathing time of $60 \mathrm{~min}$. This can be a barrier in field use because of a long operation time. Methods to facilitate the onset of drug actions seem to be needed: elevation of bath water temperature can be one plausible option, since this change will accelerate the absorption rate of drugs. This method is, at least however, applicable in disinfecting brood stock treatments in inland seed production facilities.

\section{Conclusions}

Conclusively, the suggested measure based on this study does not constitute an ultimate tool to control the STS in the field. It is also needed to refine methods to minimize adverse impacts on the ascidians being treated and on the marine environments. Despite all such limitations and accompanying legal restrictions, the results obtained for this study will be useful as one guide to develop field applicable methods against the currently helpless STS situations.

\section{Competing interests}

The authors declare that they have no competing interests.

\section{Authors' contributions}

$J G L$ carried out the initial screening of various drugs with in vitro parasite cultures. JHL and SRZ contributed to additional in vitro assays and to in vivo efficacy tests, as well. KIP and KHP designed the overall experiments and prepared the manuscript. All authors read the manuscript.

\section{Acknowledgements}

This work was supported from the fund of Fisheries Research Institute of Kunsan National University in the year of 2015.

\section{References}

Bell A. Antimalarial drug synergism and antagonism: mechanism and clinical significance. FEMS Microbiol Lett. 2005;253:171-84.

Bower SM. Disinfectants and therapeutic agents for controlling Labyrinthuloides haliotidis (Protozoa: Labyrinthomorpha), an abalone pathogen. Aquculture. 1989;78:207-15.

Cho HK, Nam BH, Kong HJ, Han HS, Hur YB, Choi TJ, et al. Identification of softness syndrome-associated candidate genes and DNA sequence variation in the sea squirt, Halocynthia roretzi. Mar Biotechnol. 2008;10:447-56.

Gilbert JP, Gratzet JB, Brown J. An in vitro method for testing synergistic action of parasiticides using malachite green and formalin as a model system. J Fish Dis. 1979;2:191-6.

Harms CA. Treatments for parasitic diseases of aquarium and ornamental fish. Sem Avian Exot Pet Med. 1996;5:54-63.

Jee BY, Lee DC. Comparative efficacy of antifungal agents for aquaculture fish and their eggs. J Kor Fish Sci. 2009;47:34-40.

Kim HJ, Park JS, Park KH, Shin YK, Park Kl. The kinetoplastid parasite Azumiobodo hoyamushi, the causative agent of soft tunic syndrome of the sea squirt Halocynthia roretzi, resides in the East Sea of Korea. J Invert Pathol. 2014;116:36-42.

Kitamura SI, Ohtake SI, Song JY, Jung SJ, Oh MJ, Choi BD, et al. Tunicate morphology and viral surveillance in diseased Korean ascidians: soft tunic syndrome in the edible ascidians, Halocynthia roretzi (Drasche), in aquaculture. J Fish Dis. 2010;33:153-60.

Klaasen CD. Principles of toxicology and the treatment of poinsoning. In: Hardman JG, Limbird LE, editors. The pharmacological basis of therapeutics. 10th ed. Seoul, Korea: McGraw-Hill; 2001. p. 67-80.

Kumagai A, Suto A, Ito H, Tanabe T, Takahashi K, Kamaishi T, et al. Mass mortality of cultured ascidians Halocynthia roretzi associated with softening of the tunic and flagellate-like cells. Dis Aquat Org. 2010;90:223-34.

Kumagai A, Suto A, Ito H, Tanabe T, Song JY, Kitamura SI, et al. Soft tunic syndrome in the edible ascidian Halocynthia roretzi is caused by a kinetoplastid protist. Dis Aquat Org. 2011;95:153-61.

Lee JG, Zeon SR, Park Kl, Choi SH, Park KH. Comparison of microscopic counting and alamar blue assay to evaluate anti-protozoal effects against Azumiobodo hoyamushi that causes soft tunic syndrome to Halocynthia roretzi. J Fish Pathol. 2013;26:31-8

Maris P. Modes of action of disinfectants. Rev Sic Tech Off Int Epiz. 1995;14:47-55.

Mason JT, O'Leary TJ. Effects of formaldehyde fixation on protein secondary structure: a calorimetric and infrared spectroscopic investigation. J Histochem Cytochem. 1991;39:225-329.

McDonnell G, Russell A. Antiseptic and disinfectants: activity, actions, and resistance. Clin Microbiol Rev. 1999;12:147-79.

Mutschuler E, Derendorf H. Drug actions. Tokyo, Japan: CRC Press; 1995. p. 799.

Park KH, Zeon SR, Lee JG, Choi SH, Shin YK, Park KI. In vitro and in vivo efficacy of drugs against the protozoan parasite Azumiobodo hoyamushi that causes soft tunic syndrome in the edible ascidian Halocynthia roretzi (Drasche). J Fish Dis. 2014:37:309-17.

Russo R, Curtis EW, Yanong RPE. Preliminary investigations of hydrogen peroxide treatment of selected ornamental fishes and efficacy against external bacteria and parasites in green swordtails. J Aquat Anim Health. 2007;19:121-7.

Shinn AP, Picon-Camacho SM, Bron JE, Conway D, Yoon GH, Guo FC, et al. The anti-protozoal activity of bronopol on the key life-stages of Ichthyophthirius multifiliis Fouquet, 1986 (Ciliophora). Vet Parasitol. 2012a;186:229-36.

Shinn A, Picon-Camacho SM, Bron JE, Conway D, Yoon GH, Guo FC, et al. The anti-protozoal activity of bronopol on the key life-stages of Ichthyophthrius multifiliis Fouquet, 1876 (Ciliophora). Vet Parasitology. 2012b;186:229-36.

Smith P. Antibiotics in aquaculture: reducing their use and maintaining their efficacy. 2012. In: Austin B, editor. Infectious disease in aquaculture: prevention and control. Cambridge UK: Woodhead Publishing; 2012. p. 161-89.

Stretton RJ, Manson TW. Some aspects of the mode of action of the antibacterial compound bronopol (2-bromo-2-nitropropan-1,3-diol). J Appl Bacteriol. 1973; 36:61-76.

Treves-Brown KM. Externally applied antimicrobial agents. In: Applied fish pharmacology. London, UK: Kluwer Academic Publishers; 2000. p. 161-79. 